\title{
Policy Considerations from a Nationwide IT-in-Education Initiative: Macedonia Connects
}

\author{
Laura Hosman
}

\begin{abstract}
Though information technology (IT) is increasingly touted as an effective tool through which governments may enhance their development efforts, to date, many IT-related deployments have remained in a pilot stage, which does little to aid governments in understanding macrolevel IT policy approaches to confronting development challenges. To address this shortcoming, this article presents a unique nationwide initiative: Macedonia Connects, a multipartner, scaled IT-foreducation project wherein every school in the country was equipped with both computers and wireless Internet connections and through which the Internet was made available to citizens across the entire country. A number of policy-related aspects of the project are identified and discussed, including the predeployment training of teachers in IT adoption, the equality of technology and training provision across the entire country, the long-term focus on the part of all stakeholders in terms of outcomes, and the business model employed in the public-private partnership. Although it is too early to discuss long-term outcomes, there are many aspects of this case that will be applicable to governments and practitioners alike in future IT-for-development endeavors. Some of Macedonia's neighboring states have already indicated interest in following this model.
\end{abstract}

KEYWORDS. Development, digital inclusion, education, Macedonia, policy

Recent years have seen an explosion in the number of information technology (IT) projects in the developing world. This IT expansion has brought with it a corresponding increase in expectations for the quality of life improvements that result from the economic empowerment and development such projects foster. Developing country governments recognize that IT-oriented initiatives can be promoted through policy, but questions remain as to effective methods for doing so, particularly on a nationwide level.

Though technology can be instrumental in development, simply "making it available" will not ensure its adoption and diffusion; a framework for its employment must be established, and, more importantly, understood. Without a thorough comprehension of exactly how IT can be applied to local economic and

Laura Hosman is Assistant Professor of Political Science at Illinois Institute of Technology. The research informing this article has been supported by a research grant, received in April 2008, from the McDowell Center for Global IT Management at the University of North Carolina at Greensboro.

Address correspondence to: Laura Hosman, Department of Social Sciences, Illinois Institute of Technology, 3301 S. Dearborn St., Chicago, IL 60616 (E-mail: laurahosman@gmail.com). 
societal situations, it becomes-or can appear to be-simply another expensive Trojan horse sent in from the developed world.

Capacity-building is absolutely necessary to build the human capital required to take advantage of advancing technologies (Lee, 2001). For this reason, schools have been a target of numerous IT-related development projects; education is a powerful tool that contributes seminally to economic growth through the development of a skilled workforce and increased productivity as well an important social force vital to the empowerment of the populace.

Most IT-related interventions in developing countries begin as pilot projects. From an economic standpoint, this is logical: The proof-ofconcept provided by a promising or successful pilot is helpful for convincing stakeholders to invest in larger projects. However, while there is logic to this strategy, there may be problems posed by the privileging of any given region, city, or school over another in terms of pilot location, particularly in societies divided by ethnic, religious, or any other differences.

One method of avoiding such difficulties is to undertake inclusive, macro-level projects-for example, by initiating a state-wide technology deployment. However, risk is inherent with this strategy as well: Projects that do not succeed will represent unfulfilled aspirations for the participants, as well as a squandering of scarce development-targeted resources on an even larger scale. Consequently, governments may be hesitant to commit limited funds to macro-level projects. The fact that a proven model does not yet exist for projects undertaken at the national level means that case studies of such endeavors, as well as lessons learned from projects of this nature, are extremely valuable. This article provides an overview and discussion of relevant policy actions from such a case: a national IT-ineducation initiative called Macedonia Connects.

In September 2005, Macedonia became the world's first "all-wireless nation." This was quite an accomplishment, as just four years earlier the country had teetered on the brink of ethnic civil war. This ambitious project was the result of a public-private partnership initiative, centered on education, called Macedonia Connects. The project provided the entire country with a broadband wireless network through a single technology deployment by connecting all 460 of the nation's schools (as well as 70 other sites, including dormitories, hospitals, and NGOs) to the Internet. Although this article will most often refer to the overall IT-in-education project as "Macedonia Connects," it was in fact just one of an ecosystem of related educational projects that were being deployed in correspondence with Macedonia Connects, which focused on awareness-raising, teacher training, curriculum development and modernization, student involvement and training, and brickand-mortar school-building modernization. The article makes the case that technology deployment alone would not have led to the levels of technology adoption and use in the schools that have resulted from a confluence of projects that expanded the undertaking's focus from one of mere technology provision to one that emphasized human capacity-building.

Among the long-term goals enumerated for the Macedonia Connects project are the promotion of a new generation of IT-literate students that, with their skills, will eventually lead the way for economic growth in the country and ultimately enable it to become a regional technology hub. Although it is often difficult to measure a direct correlation between IT use in the schools and economic development, some scholars have reported such a positive correlation, particularly for developing countries (Driouchi, Azelmad, \& Anders, 2006; Jamali, Wandschneider, \& Wunnava, 2007). In addition, there is plenty of room for economic benefits to be realized economy-wide in the longer term, because the initial deployment that connected all the schools simultaneously also enabled the provision of high-speed Internet connectivity to the entire country at affordable subscription rates, and the positive impact of increased IT inputs on economic growth and productivity has been widely noted in the economic literature (see, e.g., Cronin, Colleran, Parker, \& Dollery, 1993; Norton, 1992; Papaioannou \& Dimelis, 2007; Roller \& Waverman, 2001).

This project is unique in a number of ways. To our knowledge, this is the first nationwide IT-ineducation deployment that simultaneously connected the entire nation to high-speed Internet. The government of Macedonia sees this project as 
a long-term investment in the human capital of its youth, and seems committed to seeing this project through — and even expanding it—in the longer term. There was recognition from the outset that teacher training was a necessary component for the technology's incorporation into curriculum. Additionally, the government sought external assistance and expertise at the outset, while the project itself was designed to increase local capacities so that the project eventually would come under local supervision and control.

Because there is much to be gained from understanding the policy decisions that contributed to the project's successful deployment, this article focuses on the planning and implementation stages of the Macedonia Connects project. It leaves to future research the analysis that will be necessary to evaluate the project's sustainability and to determine whether the project will achieve its longer-term goals.

The article proceeds as follows: The next section presents an overview of the literature on the effects of IT investment and of the role of educational inputs on economic growth, and is followed by a discussion of the methodology used in this article. Following this is an overview of public-private partnerships in IT-related development projects. Next, the case study of Macedonia Connects is presented. This is followed by a discussion of the factors that contributed to the project's implementation and which can inform future policy decisions regarding IT-related development projects. The main points made in the article are summarized in the Conclusion.

\section{IT AND DEVELOPMENT: THEORETICAL FRAMEWORK}

One of the main motivations for governments to seek development-oriented IT solutions is the promotion of economic growth. A similar consideration is the economic effect resulting from educational inputs. These are important factors relevant to the Macedonia Connects project, and as such, this section presents an overview of scholarly research undertaken on these topics.

A good deal of academic work has focused on the role that IT can play to catalyze economic growth and productivity. There have been a number of macro-level studies demonstrating the positive impact of IT inputs on economic growth and development (Cronin et al., 1993; Norton, 1992; Roller \& Waverman, 2001). The majority of such analyses has utilized data from the developed world. Only a limited number of studies has addressed the same issues as they apply to developing world countries, and until recently, most of these studies have presented mixed results.

Dewan and Kraemer's (2000) findings indicate positive and statistically significant returns to IT capital investments for developed countries, but nonsignificant results for developing countries. The authors conclude that developing countries lack a substantive base of capital stock and infrastructure necessary for IT investment to bring about a positive result. In a similar vein, Pohjola's (2001) cross-sectional study across 39 countries from 1980-1995 reveals that IT investment has no significant impact on economic growth when all the countries are included, but when he removes the developing countries from the sample, he finds a strong influence on growth from IT investment in the developed countries. Specifically addressing the digital divide and growth gap between developed and developing countries, Seo and Lee (2005) present mixed findings as well. On the one hand, global digitalization has a negative impact as it widens the existing digital divide, but on the other, there is room for positive impacts through knowledge spillovers that can promote growth in the developing world.

Papaioannou and Dimelis (2007) make an important contribution with their finding that IT exhibits a positive and significant impact on productivity around the globe. Theirs is the first study to give evidence that IT's positive returns to productivity, long a reality for the developed world, have now begun to evidence themselves in the developing world as well. Hosman, Fife, and Armey's (2008) findings are along the same lines: They demonstrate positive gross domestic product (GDP) per capita returns to IT investment across 42 developing world countries from the period of 2000-2006. Since these findings were more robust than when the same regression was run earlier using data from 2000-2004, their 
conclusion is in line with Papaioannou and Dimelis's assertion that "developing countries have started to benefit from IT" (2007, p. 180).

Therefore, a turn seems evident in the literature, as a greater number of scholars are beginning to report positive returns to IT investments in developing countries. Yet investment into IT is only half of the story, for IT's impact on growth depends not only on its own level, but also on the level of other complementary factors (Edwards, 2002). Perhaps the most important of these factors is the level of human skills and capabilities required to make use of the new technologies. The most effective method for states to develop such capacities is through education (Jamali et al., 2007; Lee, 2001).

Limited numbers of economics scholars have investigated the interrelatedness of education and IT, among other inputs, in affecting economic growth. Driouchi et al. (2006) find that the performance of national economies is closely linked to investments in knowledge-related inputs (p. 241), and, in fact, for developing countries, they find increasing returns to scale for such investments (p. 248). Their findings lead them to recommend that policy efforts in developing countries be directed toward, among other things, expanded education and future investments in information infrastructure (p. 249).

In their study of the effect of political regimes and technology on economic growth, Jamali et al. (2007) find that democracies significantly outperform autocracies in this area, and so the type of government matters a great deal regarding economic growth. They also find that there are two other main determinants for economic growth: human capital and technology. Countries can increase their level of economic growth by increasing levels of education and technology in the economy (p. 1425).

Nomura (2007) cautions against oversimplifying measures of educational inputs, however, and points out that the majority of empirical studies regarding education and economic growth fail to account for the quality of education, and rather, simply measure the quantity. Yet with education, it may be the case that quality matters a great deal more than quantity. To wit, if the desired educational outcome is a technologically literate populace and there is no technology in the schools, then increasing the amount of education will not help to meet this goal. Nomura further finds that countries with low levels of educational equality did little to improve their levels of economic growth, while the highest returns to educational inputs were realized in countries with the highest improvements in educational quality (2007, p. 629).

Still, economic growth is but one area of human development. However, we are not aware of studies that measure the effect on human development (including social, political, and quality of life outcomes) that results from increased investment in IT and educational inputs. This is neither a trivial nor frivolous area of research, however, and this will be an important area for future studies.

Though many of the scholars cited above make general policy recommendations, it is one thing to advocate for increased investment in education, and another thing entirely to put such a policy into place. Understanding the nuts and bolts of effectively designing and carrying out an educational project designed to increase technological capabilities on behalf of all students in a country is a complicated undertaking. The issues and actors involved are manifold and comprise infrastructural and regulatory issues, political and institutional considerations, and pedagogical and technological concernsand this is by no means a complete list. This is where case-level analysis becomes a necessary complement to macro-level studies.

\section{METHODOLOGY}

Gerring defined the case study - the methodological choice for this article-as "an intensive study of a single unit for the purpose of understanding a larger class of similar units" (2004, p. 342). As the most appropriate method for studying the "many variables-small N" type of subject presented herein (Lijphart, 1971), and allowing for the intensive analysis of data from a limited number of cases, the qualitative case study is particularly relevant to work involving the development of emerging economies. In addition, the case study methodology is particularly suited to theory building and best 
practices identification; as research is notably lacking in this area (de Silva \& Zainudeen, 2007; London \& Hart, 2004), detailed analysis is necessary groundwork for future work and understanding of the causal chain(s) involved.

The research findings presented in this article are based on a combination of secondary literature review and firsthand fieldwork methods, such as direct observation, and interaction and interviews with project managers and practitioners, teachers, school administrators, and policymakers. The fieldwork was carried out between April and May of 2009, while secondary research and preliminary interviews were carried out from October 2007 through April 2009.

The secondary literature analyzed comprises policy documents, such as the United States Agency for International Development (USAID) evaluative publications, survey results, and policy documents, as well as both scholarly and news journal articles. Though this is not a comprehensive list, those interviewed on-site included the following: Teachers and administrative officials from primary and secondary schools, ranking officials from the Macedonian Ministry of Education, the Ministry of the Information Society, the Agency for Electronic Communications Regulatory Authority, the on-site project director responsible for the Macedonia Connects project deployment, as well as the post-deployment project director, the executive director of a Macedonian NGO responsible for part of the predeployment educational training, and Chiefs of Party from the USAID-sponsored Primary Education Project and Secondary Education Project, as well as other senior program directors and project managers at the related IT-in-education and technology promoting projects. The Macedonian case was chosen on the basis of its uniqueness, in terms of the project's scope, stated goals, and business model. These will be elaborated upon in the case study.

There can be inherent difficulties in extrapolating from a single case study. What has been successful in one geographical location may be completely inappropriate for another. History has demonstrated that development is a multifaceted, complex process rooted in the sociocultural, political, economic, and historic reality. Any attempt at policy prescription must be preceded and informed by a sincere effort to understand the particular situation at that point in time, and of how it got there, on both a recent and historical time scale. We are mindful of this limitation.

Additionally, when utilizing case studies, it is important to be able to test the applicability of findings across similar cases. Such testing will remain a challenge for future research, yet it is the author's intention to apply these findings across future cases to test their applicability. Given that USAID, a number of Macedonia's neighboring states, and multiple African states have already taken preliminary steps to pursue projects that follow the Macedonia Connects model (Bilbilov, 2009; Strachan, 2008), we are confident that the number of such cases will grow.

\section{PUBLIC-PRIVATE PARTNERSHIPS}

There is not (yet) a theoretical framework that focuses specifically on public-private or international partnerships (Stewart \& Gray, 2006). However, such partnerships have become increasingly important in the IT and development context, and the case at hand employs such a partnership. Accordingly, this section provides an overview of public-private partnerships (PPPs), specifically in the field of IT and development.

PPPs-agreements between private-sector, for-profit businesses and developing country public sector actors-are currently held in extremely high esteem by those seeking IT solutions to development challenges. These partnerships enjoy broad support and are promoted by governments, international organizations, nongovernmental organizations (NGOs), and private firms alike. In fact, the United Nations Millennium Declaration specifically recommends the creation of PPPs to "ensure that the benefits of new technologies, especially information and communications technologies ... are available to all" (Weigel \& Waldburger, 2004, p. xv).

Developing a theoretical framework for the study of exactly what a partnership business model should be is of paramount importance; 
a thorough understanding of the PPP model will, no doubt, help to explain why a large number of such initiatives fail (Angerer \& Hammerschmid, 2005). (That elusive understanding is, unfortunately, hindered by the high incidence of underreported failures as well as by lack of research.)

The synergy created by the combination of a private partner's resources with the administrative acumen and political power of government-in what is generally viewed as a business relationship - can, ideally, improve public services and the management of public sector assets (Gerrard, 2001) in a manner and to an extent impossible to achieve by a single party acting alone.

The 2002 United Nations World Summit on Sustainable Development established guiding principles for sustainable development partnerships (Kara \& Quarless, 2002). As these types of partnerships originated among environmental and developmental scholars, the concept of sustainability has long been a key one (Stewart \& Gray, 2006); other fields of study have recently begun to appreciate its importance.

One major concern regarding PPPs in the developing world is that they will not address the larger issues of socioeconomic development and poverty eradication if they are not sustainable or relevant in the daily lives of their intended beneficiaries. Kanungo (2004) reports that private-sector participation in such projects has not demonstrated better results than previous public-sector-only initiatives. Yet, we assert that when public-private initiatives are well thought out, technologically appropriate, and designed with long-term sustainability and the empowerment of the localities in mind, they have the potential to enable real socioeconomic benefit.

Of course, for a given IT project to be successful, and therefore sustainable, locally appropriate technology must be deployed. "Locally appropriate" in this case refers both to the wants and needs of the technology recipients as well as to what is possible given the physical, geographical, and/or infrastructural reality on the ground. In the case of Macedonia Connects, the technology may be considered locally appropriate in that there is already a strong emphasis on universal education within the state, a high literacy rate (at 96 percent), and the infrastructure necessary to support the project is already in place, in terms of sufficient school buildings, classrooms, teachers, electricity, and roads - all of which facilitate deployment. In addition, during the build-up to project implementation, the government liberalized and created regulatory policy for the telecom sector, which enabled affordable connectivity not just for the schools, but for the population in general.

\section{MACEDONIA: CONTEXTUAL OVERVIEW}

The former Yugoslav Republic of Macedonia is a landlocked, mountainous country located in Southeastern Europe, with over 2 million inhabitants and occupying approximately 25,000 square kilometers. The country gained its independence from Yugoslavia peacefully in 1991 and has been a democratic state ever since, yet it suffered severe economic difficulties following its independence when the Yugoslav internal market collapsed and subsidies from the former central government ceased. The Republic still has one of the lowest percapita gross national incomes in Europe, at $\$ 9,950$ in current U.S., dollars and is considered a lower-middle income country (World Bank, 2008).

Since about 1996, Macedonia has witnessed steady, though slow, economic growth and has undergone considerable economic reform since independence. The country has developed an open economy, with trade accounting for upwards of 80 percent of GDP in recent years. Despite the progress it has made however, Macedonia still faces a high unemployment rate, at 35 percent (CIA Factbook, 2010), while 22 percent of the population lives below the poverty line (World Bank, 2008). Corruption and a relatively ineffective legal system also act as significant restraints on successful economic development.

In addition to economic challenges, Macedonia has faced many of the same social problems faced by other former socialist East European countries during the transition to both a market 
economy and democracy. Under centralized Yugoslavian rule, ethnic groups were more or less forced to tolerate one another, and the expression of cultural differences was suppressed. Since Yugoslavia's dissolution, however, these groups have asserted their independence to a far greater degree. According to a 2002 census, Macedonia's population comprises approximately 64 percent ethnic Macedonians, 25 percent ethnic Albanians, 4 percent Turkish, 3 percent Roma (Gypsy), 2 percent Serb, and 2 percent other (State Statistical Office, 2003).

\section{THE PARTNERSHIP}

The Macedonia Connects case is a PPP consisting of four main partners: USAID, the Academy for Educational Development (AED, a Washington, DC-based nonprofit organization), On.Net (a Macedonian startup telecommunications service provider), and Macedonia's Ministry of Education and Science. The project's initial funding came from USAID, which paid for the deployment, teacher training, and school connectivity for the first three years of the project (after which time the Macedonian government was to assume the schools' connectivity fees). The nonprofit AED was responsible for managing overall project implementation, while the private partner, On.Net carried out the deployment of infrastructure, and was charged with becoming profitable in three years' time through the subscription services it was enabled to offer to the public. In this way, the project is designed to become sustainable in the long run.

USAID, through its Last Mile Initiative, has been funding a number of country-specific IT projects that make use of new, creative, and promising approaches for expanding telecommunications access that are designed with a business model such that once they are up and running and USAID's funding stops, the projects will be self-sustainable. This type of project marks a shift on the part of USAID, which now recognizes that correct incentives should be in place for aid-based funding to be effective; a project is more likely to be a success once all parties feel they have a stake in the outcome-in other words, involving all parties as stakeholders. In fact, such incentivizing represents a radical departure for USAID: Traditionally, U.S. firms merely extracted aid fees from the initial implementation of a project, and had little-to-no interest in the impact or sustainability of the project after the funding dried up.

This particular project is structured to build local capacities and expertise such that once the three-year timeframe for project implementation and funding has elapsed, the project will continue to be run under the aegis of local entities. The private partner, On.Net, has a limited duration of time during which it must "prove the concept" and become a profitable business. The private partner in this case is a local firm, with a great deal of interest in the socioeconomic growth potential this project offers to Macedonia, as well as in seeing its own business become profitable. The public partner, Macedonia's Ministry of Education and Science, has received assistance in its aim of modernizing teaching methodologies and integrating computer technology into the classroom and curriculum. This assistance is limited in its duration, and the Ministry must ultimately assume these responsibilities on its own as it progresses in its goal of becoming compliant with European Union educational standards. The aligning of incentives matters a great deal in partnerships, and this case is no exception.

\section{CASE STUDY: MACEDONIA CONNECTS AND ESCHOOLS}

The initial idea for placing computers in Macedonia's schools dates back to May 2002, when then-President Boris Trajkovski-a strong believer in the need for Macedonian children to learn modern IT skills-returned from an official visit to the People's Republic of China (PRC) with the promise of a donation of nearly 6,000 computers from the PRC. Microsoft later donated over 6,000 licenses for software (Nairn, 2006).

Still, the president realized that if there was no Internet connection for these computers, the 
project's potential would remain severely limited. He approached USAID, which had been funding projects in the country for over a decade. USAID in turn approached the AED to manage the project deployment. Two complementary USAID-sponsored programs were created as a result of the president's initiative: eSchools and Macedonia Connects.

The eSchools project was composed of two parallel activities: technology deployment on the one hand, and ICT curriculum development and integration, as well as teacher training, on the other. The technology deployment began in 2004 with the installation of computer labs at all 91 secondary schools across the country. Each school first had to give evidence that it could provide the necessary security, electricity, and a classroom for the lab. Once an assessment team visited each school and determined its infrastructural readiness, the schools received an eSchool computer lab, consisting of 20 of the PRC-donated computers, which was set up and installed by the eSchools project team.

The second phase of the eSchools project provided training for teachers in the newly developed information and communication technologies (ICT) curriculum, in order to improve the quality and relevance of using ICT in teaching. Two teachers from every school received this ICT training. They also received instruction in order to become "teacher trainers" themselves, and they were to return to their home regions and home schools and train a greater number of teachers in ICT integration. This cohort of 180 "teacher trainers" completed their training in August 2005. In the same year, the eSchools project began its expansion to cover all 360 primary school facilities as well (Nikolovska, 2009). In the meantime, the Macedonia Connects project to connect all of these schools to the Internet was beginning to take shape.

From the outset, the Macedonia Connects project focused on connecting the nation's schools. However, it quickly became clear to a small group of top-ranking officials from the partner organizations (USAID, AED, eSchools, and Macedonia Connects) that because the schools are distributed across the country, this project could also, through the very same deployment, provide nationwide connectivity. This group proposed the idea that the schools be leveraged as anchor tenants to provide a nationwide network. Thus the project's capital financing could be made doubly effective by simultaneously being used to build out the school network and to provide connectivity to all other potential constituent markets (Bilbilov, 2009; Strachan, 2007).

Before the project could proceed, however, there was the problem of the high prices and limited availability of telecom services within the country. This was due to the monopoly presence of MakTel (a Hungarian-owned subsidiary of Deutsche Telecom) in Macedonia's telecom sector. With no competition from other providers, there was simply no incentive for the monopoly to expand services or offer affordable telecom rates; little more than half the country had Internet coverage, and MakTel charged as much as $\$ 150$ per month for dial-up Internet services-a truly prohibitive fee when monthly salaries averaged around \$200 (Hunsberger, 2006; Kampschror, 2006). A strategic goal of USAID's Last Mile Initiative-its global program launched in April 2004 to bring modern telecommunications infrastructure to areas that traditionally have been underserved-is to promote competition and the breakup of legacy telecom carriers.

In December 2004, USAID issued a request for bids to implement the project. Because it was a monopoly, MakTel was not allowed to bid, but it then aggressively attempted to derail the project. Its predatory tactics included the following: Sending employees, posing as Macedonia Connects staff, to schools to attempt to sign them up for MakTel service; initiating a publicity campaign claiming that it was already providing free Internet service to all of the schools (which it was not); and making large contributions to politicians and/or threatening the government that it would lose MakTel's annual \$51 million in dividends, all in the attempt to block pending legislation to break up the monopoly (Strachan, 2007).

In the end, the strong-arm tactics proved unsuccessful. It likely helped matters that Macedonia already had a mandate from the 
European Union (which the country is attempting to join) to change the monopoly status of its telecom sector and to establish a regulator and regulatory laws. The government hired an American consulting firm, Booz Allen Hamilton, to advise it on the regulatory aspects of the newly proposed laws. In the end, the legislation that established competition, a regulator, and the freeing up of high-speed bandwidth from monopoly control in Macedonia's telecom sector eventually passed through the legislature with a vote of 82-0 (Strachan, 2007).

From the bids submitted, USAID selected a local start-up Internet service provider (ISP), On.Net, to carry out the nationwide broadband installation, with a mandate not only to provide Internet to the schools, but also to develop and market these services nationally to businesses and individual customers (Shamblin, 2005). One major reason for this dual focus had to do with the project's long-term sustainability. USAID subsidized the schools' connectivity fees for the first three years of the project. During this time period, the ISP was charged with becoming a profitable, sustainable business, which it needed to accomplish through the collection of individual and business subscription fees.

On.Net selected Motorola Canopy technology to provide the wireless connectivity, and used Macedonia's mountainous terrain to its advantage: connection points were sited on mountaintops across the country. The project team assisted the effort by engaging local small-scale IT companies across the nation to assist with the deployment. A competition was initiated; the country was divided into four regions with the same number of schools in each region and the same number of IT companies (eight) per region. Each IT company had to provide Cisco-certified installers to participate, and these installers had to work together to complete the task. This strategy thus promoted the companies' investments in the human capital training of their employees in order to receive the development-related funds, and also promoted networking and collaboration among local businesses across regions (Bilbilov, 2009). Since Macedonia's physical infrastructure was favorable for the deployment, as described above, and a large number of motivated, trained, and certified installers were involved, the entire project's deployment was completed within four months, in time for the start of the 2005 school year.

In order to further promote IT integration into the schools' curriculum, USAID ultimately sponsored the training of 14,000 teachers in basic IT skills and in the incorporation of IT into the curriculum and classroom (Nikolovska, 2009). This eSchools initiative was described as part of the Macedonia National Education Development Strategy, which would base the educational process on the principles of interactive teaching, with a focus on creative learning, critical thinking, problem-solving, and implementation of modern education technology (Education Development Center, 2006). The three components of the training were designed to promote project-based learning, IT integration into curriculum, and community linkages.

Participants' activities included writing blogs, Web publishing, learning how to use specific software, group projects and presentations, and rewriting their curriculum plans for the following academic year to emphasize IT integration, problem-based learning, and communitybuilding (Education Development Center, 2006). A further goal of the project was to bring Macedonia's educational standards into a framework of accepted European practice in technology-supported learning - another example of European Union standards providing the impetus for moving forward. This project is to be maintained by the four pedagogical and teacher training faculties from three Universities in Macedonia, which likely means that student-teachers will undergo similar training in the future.

Another aim for the eSchools project was to promote teacher collaboration and communication across schools, via the Internet, and to create locally relevant educational content, available online, of which teachers could make use. This aim was addressed through a Web site portal that was co-created by the eSchools and Macedonia Connects project teams, and that was launched in the spring of the program's first academic year. As part of their training, all primary school teachers were required to create 
and implement a lesson plan that incorporated IT into their curriculum. They then uploaded their lesson plans to the portal, where other teachers could search for and make use of these plans themselves. In total, 18,000 lesson plans were posted for public use. The portal also provided Web space for blogs and e-mails, and provided a forum where teachers could post topics and discuss them. In addition, each school could upload and maintain its own Web site. These Web site functions were used extensively during the years that USAID and its partners administered the project. However, at the time of the fieldwork, the Web site had been transferred to control of the Ministry of Education, which was not maintaining the site. However, the Ministry reported plans to expand such functionality on a new Web site in the future.

As a result of having the new technology at its disposal, a group of Macedonian high school students won a global competition, Doors to Diplomacy, sponsored by the U.S. State Department in 2006 (Fenner, 2006). The aim of the competition was to create a Web site that teaches the importance of international affairs and diplomacy. The subject of the Macedonian students' Web site was the experiences of children living in poverty around the globe (Fenner, 2006).

In 2007, seven education professors from Indiana University visited Macedonia to help promote modern teaching methods of science and math, particularly at the middle-school level (Indiana University, 2007). This visit was also sponsored by USAID and was part of an overall program in Macedonia aimed at the revision of curriculum and assessment methods and the incorporation of technology. After their return to Indiana, the professors have kept in touch with the Macedonian teachers for the duration of the five-year project through teleconferences (Indiana University, 2007) — certainly an example of increased international communication through technology. At the time of the field research, this project was ongoing.

As was mentioned above, Macedonia Connects (and eSchools) comprised part of an ecosystem of related and concurrent programs in Macedonia that focused on integrating IT use into the educational system. These programs included the Secondary Education Project and Primary Education Project (both of which are USAID/AED driven initiatives), whose undertakings include building renovation and energy efficiency promotion for schools, improving school-based assessment through the use of technology, increasing technology-related workforce development skills in students, improving the curriculum for math and science education through the use of technology, and promoting student training and interest in technology through extracurricular Student Support Technician Clubs, wherein students are trained in basic computer maintenance, network management, and teacher assistance.

Thus, although the Macedonia Connects project itself was mainly technology-focused, it contributed to a larger human capacity-building endeavor within the educational system, and within the state as a whole. This is an important consideration for states looking to replicate the Macedonia Connects model for providing IT and Internet to schools.

\section{INITIAL OUTCOMES}

As a direct and immediate result of the Macedonia Connects project and the competition it created in the broadband sector, highspeed Internet became available within a matter of months across the entire country, and monthly service rates for local businesses and households (anywhere in the country) dropped to 25-35 Euros per month. (These figures should be considered approximations, as they were quoted to the author during interviews in either Euros or U.S. dollars, whereas Macedonia's official currency is the denar.) This improvement is to be compared with the situation before competition was legislated, when the incumbent monopolist had no incentive to invest in providing high-speed Internet to the public, and therefore did not. In 2004, over half the country's population had no access to high-speed Internet, and the incumbent was charging up to 150 Euros per month for dial-up Internet service. At present, due to even more competition, high-speed Internet subscription rates have 
dropped to a range of 10-35 Euros per month, depending on the level of service or data use.

In the years following the Macedonia Connects deployment, On.Net, the local ISP charged with becoming a profitable entity within three years, was taking on new clients at a rate of 1,500-2,000 per month (Strachan, 2007). In March 2006, a majority share of On.Net was acquired by Telecom Slovenia, which has resulted in Macedonia's broadband Internet market becoming a competitive duopoly at present, although there are a number of smaller ISPs operating as well. The start-up's purchase by an established regional telecom leader is, in fact, a strong indicator of On.Net's attractiveness - and potential for profitabilityas a company.

In addition to falling high-speed Internet prices due to competition, the number of both Internet subscribers and Internet users in Macedonia increased markedly in the brief period of time since this project was deployed in 2005. According to the International Telecommunications Union (2008), the number of Internet subscribers in Macedonia rose from 5.3 to 16.3 percent between 2005 and 2007, while the number of Internet users rose from 7.8 to 33.6 percent over the same period, as illustrated in Figure 1.

In December of 2006, the Macedonian government announced a new and ambitious initiative-at least partially based on the success of the Macedonia Connects project, according to the Ministry of the Information Society-to provide a computer to every student in primary and secondary schools across the country, called the Computer for Every Child Initiative. This would effectively decrease the student-tocomputer ratio from, currently, $1: 56$ to $1: 1$ or $1: 2$, and would require the purchase of between 150,000-180,000 new machines.

By late Spring of 2007, the government had put forth an open bid process, and the tender for the project was ultimately awarded to another PPP made up of NComputing (a Silicon Valley, California-based virtualization software and hardware company), Haier (a Chinese PC manufacturer), and Accent (a Macedonian integration and support firm). This group works together with the Ministry of Education and the

FIGURE 1. Internet use in Macedonia 2000-2007. Source: International Telecommunications Union (ITU), Indicators, ICT Statistics Database, 2008.

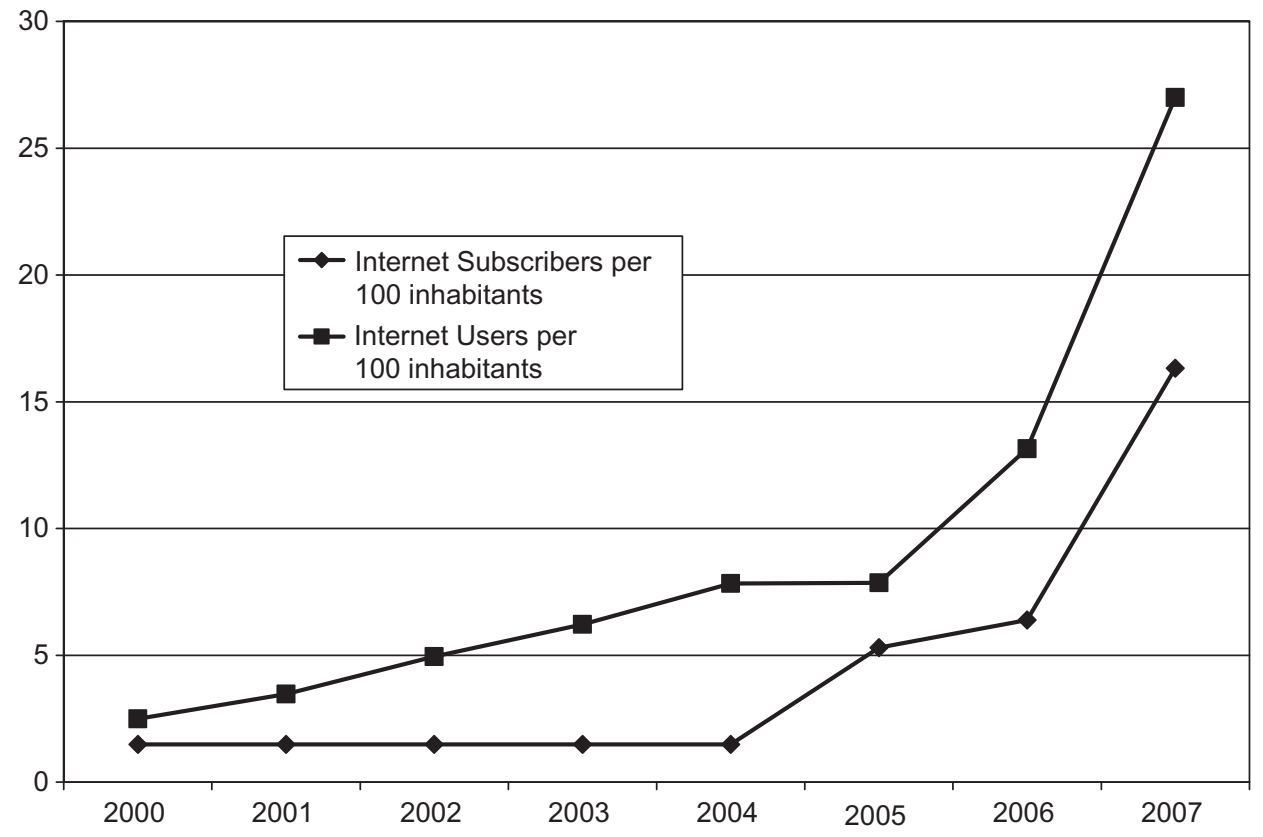


Minister of the Information Society to implement the new project.

NComputing's technology allows seven students to share one PC hard drive simultaneously. Each user station consists of a monitor, mouse, keyboard, and speakers that are connected to the hard-drive device (the actual device is a box that attaches to the back of one of the terminals, to which six other user stations are connected).

In two signs of the public's support for the project, the government in power ran, in part, on the platform of the computers-in-schools projects, and the June 2008 reelection of the government in power was seen as a reaffirmation of public support for these IT-in-theschools initiatives. Additionally, on July 9, 2008, the newly sitting Macedonian Parliament passed a bill that created a new Information Technology Ministry.

Another phase of the new plan is for the government to give full scholarships to 5,000 Macedonian students who are interested in studying IT at the university level in Macedonia. This plan, which is also to be implemented across the entire country, on an equal basis, demonstrates evidence of forethought to prevent the best and brightest young people from leaving their native country due to lack of opportunities at home, also known as "brain drain," which is a concern across the former Yugoslav countries.

\section{POLICY CONSIDERATIONS}

Since the Macedonia Connects project was completed and handed over to the Macedonian Ministry of Education in 2007, no in-depth assessment or follow-up evaluation has taken place. For this reason, it is too soon to comment on long-term outcomes of the project. Yet, it will offer a valuable opportunity for measurement and evaluation of outcomes in the future. Even so, much can be learned from the planning and implementation stages of this project, as well as the policy considerations that have had bearing on this project to date. These may serve as valuable lessons learned for future projects of a similar nature.
First, in terms of the policy recommendations made in the literature review above, Macedonia Connects meets or exceeds these recommendations. For example, Nomura (2007) emphasizes that states should focus on both quality and equality in education. The Macedonia Connects project both deployed computers and provided IT training on an equitable basis across the country, in the attempt to improve both equality and quality of education. Lee (2001) recommends that "to eliminate the digital divide, we need to not only make computers accessible but also secondary education available" (p. 148). The Macedonia Connects project has made computers accessible at all levels of the schools within an educational system where primary and secondary education is universally available. Finally, in line with Jamali et al.'s (2007) findings that democracy, technology, and education are all important determinants of economic growth, Macedonia benefits from a democratic government, and technology and education are precisely the focus of the Macedonia Connects project.

In terms of governmental action, legislating for competition in and regulation of the telecom sector was a crucial contributing factor to Macedonia Connects being realized at all. Though it is not possible to set up a control group that did not legislate for competition in the telecom sector, it is generally agreed that competition tends to drives down prices for consumers. This turned out to be the case in Macedonia. However, the benefits of a liberalized telecom sector go far beyond this particular project. One unique aspect of the telecom/IT industry is that its growth, output, and technological adoption by other sectors and by individuals in the economy enables these sectors (and individuals) to perform their own functions more efficiently, promoting growth and productivity. All of this is enhanced through increased competition, which drives up innovation and drives down costs. Consequently, efforts made in the IT arena will have positive repercussions across the economy and in social dimensions as well.

The government's public show of support for the project is also important for its long-term success and sustainability. In fact, the government's 
support of this project is so strong that it based part of its re-election platform on the computers in schools initiatives and has begun the process of expanding the project to one computer per child. It has also created a Ministry of Information Technology, which should add even greater support to the nation's goal of becoming a regional technology hub.

The stakeholders of this project have recognized how important it is for pedagogy and technology to meet, and that this project's success depends on a long-term commitment to technology incorporation and adoption to develop the human capital and capacity-building necessary for sustainable economic growth. In terms of best practices of the partners and partnership, the training of teachers in the incorporation of technology into their curriculum prior to implementation was perhaps the most important human capacity-building aspect of the project, and will go a long way in determining whether computers will actually be meaningfully adopted in the schools.

The business model employed in the partnership also represents a best practice, in that the incentives are aligned to promote sustainability. The project took advantage of the intersection of common interests by the parties involved. Leveraging partnerships where each party brings its own expertise to the project seems here to have offered the potential for pedagogy and technology to meet. Utilizing limited development funds to equip schools and simultaneously provide broadband Internet access to the entire population is a creative, effective, and original cost-saving method that deserves to be investigated by future development-oriented project stakeholders.

Macedonia Connects also benefited from the clear enumeration of goals from the outset of the project. These were recognized to be longterm in nature, and the stakeholders involved appear to be committed to seeing this project as the human capacity-building effort that it is. USAID and AED's involvement in the project had an end date that was built in to the project's plan-it is now under local control.

One success factor that is often identified in IT-related development projects is the involvement of local stakeholders and the promotion of bottom-up input to establish feedback loops. The case presented here was, in fact, a top-down initiative, with USAID funding the project, AED being responsible for its management and implementation, and the Ministry of Education now running the project. However, since the majority of project team members were Macedonians, all of the planning and design phases allowed for local involvement and input from the very beginning. School principals, teachers, and even students were encouraged to make suggestions (Hunsberger, 2006, p. 50). Also, since education is a public good, governmental initiative and involvement are in line with the project's national policy objectives.

There is also an emphasis in the IT-anddevelopment literature on the inclusion of rural areas in development-oriented projects. This project included all schools across the country, providing the highest level of inclusion possible. The deployment ensured that even remote areas are now connected to the Internet, and service is available to these residents at uniform rates and speeds no matter where they live.

Still, there will be numerous challenges ahead as the project continues to expand, for example, the process of scaling to accommodate a computer for every child will present new and different issues. As stated above, the outcomes of the expanded project have not yet been subject to systematic evaluation or measurement. It therefore presents a unique opportunity for further research in order to measure outcomes and gauge progress toward goals.

\section{CONCLUSION}

This article presented a case study of a unique, nationwide, education-focused IT deployment that provided Internet connectivity to the entire country of Macedonia by connecting all of the schools within its borders. Both equipment and training were provided on an equitable basis to all schools, teachers, and students.

Though the focus of the project was on education, the project utilized the same deployment to provide the possibility of affordable highspeed Internet to all citizens across the country at the same time. This dual-purpose deployment 
is not just an efficient use of development funds; it is an efficient method for providing IT tools to citizens in order to promote economic growth. Even so, as noted in the literature, human capacity-building is a necessary complement to IT provision in order to enable people to make use of the technology. This project bodes well for such uptake, since it focuses on training the entire generation of youth with IT skills through the education system.

The project thus effectively allows for IT to contribute to the national economy, in the shorter term by the provision of IT where it did not exist before, and in the longer term, through the education of the youth in how to take advantage of it. Macedonia Connects made use of an innovative business model in the form of a PPP that resembled a venture capital model, and was designed to become profitable by the end date for the international partners. The project is now locally run.

It is recognized that results from the project will not manifest themselves overnight, and all of the stakeholders appear committed to the long-term realization of the project. For these reasons, the case is considered successful, as well as one that presents best practices for future, similar endeavors, both regionally and around the globe. Numerous policy considerations have been discussed, and this project offers a great deal of practical insight for future IT-related development projects.

Recognizing the potential that Macedonia Connects represents, regionally proximate countries such as Albania, Georgia, and Bosnia-Herzegovina have expressed interest in replicating the project within their own borders using the partners involved with the Macedonia project. Even so, many questions and lines of inquiry, including an analysis of the outcomes of this project, remain for future work.

\section{REFERENCES}

Angerer, D. J., \& Hammerschmid, G. (2005). Public private partnership between euphoria and disillusionment: Recent experiences from Austria and implications for countries in transformation. Romanian Journal of Political Science, 5(1), 129-159.
Bilbilov, A. (2009). Technology Transfer Program Manager, Macedonia Connects. Interviews with the author, April 29 and May 13, 2009.

CIA Factbook. (2010). The world factbook. Central Intellegence Agency 2010. Retrieved March 21, 2010, from https://www.cia.gov/library/publications/ the-world-factbook/geos/mk.html

Cronin, F. J., Colleran, E. K., Parker, E. B., \& Dollery, B. (1993). Telecommunications infrastructure investment and economic development. Telecommunications Policy, 17(6), 415-430.

de Silva, H., \& Zainudeen, A. (2007, December). Teleuse on a shoestring: Poverty reduction through telecom access at the bottom of the pyramid. Paper presented at the Centre for Poverty Analysis Annual Symposium on Poverty Research, Colombo, Sri Lanka. Retrieved August 9, 2007, from http://www.lirneasia.net/wp-content/uploads/ 2007/12/desilvazainudeencepaprfmar07_v30.pdf

Dewan, S., \& Kraemer, K. L. (2000). Information technology and productivity: Preliminary evidence from country-level data. Management Science, 46, 548-562.

Driouchi, A., Azelmad, E. M., \& Anders, G. C. (2006). An econometric analysis of the role of knowledge in economic performance. Journal of Technology Transfer, 31, 241-255.

Education Development Center. (2006). Technology implementation in Macedonia. Retrieved June 3, 2008, from http://main.edc.org/newsroom/features/ macedonia_technology.asp

Edwards, S. (2002). Information technology and economic growth in developing countries. Challenge, 45(3), 19-43.

Fenner, L. (2006). Students in Macedonia, Ghana win state department award. Retrieved June 3, 2008, from http://www.america.gov/st/washfile-english/ 2006/June/20060606154430xlrennef0.3896143.html

Gerrard, M. (2001, September). Public-private partnerships. Finance and Development, 48-51.

Gerring, J. (2004). What is a case study and what is it good for? American Political Science Review, 98(2), 341-354.

Hosman, L., Fife, E., \& Armey, E. (2008). The case for a multi-methodological, cross-disciplinary approach to the analysis of IT investment in the developing world. Information Technology for Development, 14(4), 308-327.

Hunsberger, K. (2006, June). A country connects. PM Network, 46-54.

Indiana University. (2007, July 3). IU professors in Macedonia to help shape math and science education. Retrieved June 3, 2008, from http://newsinfo.iu.edu/ news/page/normal/5943.html

International Telecommunication Union. (2008). ICT statistics database. International Telecommunication Union. Retrieved July 9, 2008, from http://www.itu.int/ITU-D/ ITeye/Indicators/Indicators.aspx\# 
Jamali, K., Wandschneider, K., \& Wunnava, P. V. (2007). The effect of political regimes and technology on economic growth. Applied Economics, 39, 1425-1432.

Kara, J., \& Quarless, D. (2002). Guiding principles for partnerships for sustainable development. Annex to the Vice-Chair's summary of the informal meetings on partnerships for sustainable development. Retrieved June 6, 2007, from www.johannesburgsummit.org/ html/documents/precom4docs/bali_documents/annex_ partnership.pdf

Kampschror, B. (2006, March 28). From warfare to wireless in Macedonia. The Christian Science Monitor. Retrieved March 29, 2006, from http://www.csmonitor.com/2006/ 0328/p07s02-woeu.htm

Kanungo, S. (2004). On the emancipatory role of rural information systems. Information Technology \& People, 17(4), 407-422.

Lee, J. W. (2001). Education for technology readiness: Prospects for developing countries. Journal of Human Development, 2(1), 115-148.

Lijphart, A. (1971). Comparative politics and the comparative method. The American Political Science Review, 65, 682-693.

London, T., \& Hart, S. L. (2004). Reinventing strategies for emerging markets: Beyond the transnational model. Journal of International Business Studies, 35, 350-370.

Nairn, G. (2006, March 28). Broadband network is the envy of the west. Financial Times London. Retrieved March 21, 2010, from http://www.ft.com/cms/s/2/e6b2fd14bd97-11da-a998-0000779e2340,dwp_uuid=ebad1468bf17-11da-9de7-0000779e2340.html

Nikolovska, Z. (2009). Chief of Party, eSchools Macedonia. Interview with the author, May 16, 2009.

Nomura, T. (2007). Contribution of education and educational equality to economic growth. Applied Economics Letters, 14, 627-630.

Norton, S. (1992). Transaction costs, telecommunications, and the microeconomics of macroeconomic growth. Economic Development and Cultural Change, 41(1), 175-196.
Papaioannou, S., \& Dimelis, S. (2007). Information technology as a factor of economic development: Evidence from developed and developing countries. Economic Innovation and New Technology, 16(3), 179-194.

Pohjola, M. (2001). Information technology and economic growth: A cross country analysis. In M. Pohjola (Ed.), Information technology and economic development (pp. 242-256). Oxford, England: Oxford University Press.

Roller, L., \& Waverman, L. (2001). Telecommunications infrastructure and economic development: A simultaneous approach. The American Economic Review, 91(4), 909-923.

Seo, H. J., \& Lee, Y. S. (2005). Contribution of information and communication technology to total factor productivity and externalities effects. Information Technology for Development, 12(2), 159-173.

Shamblin, L. (2005). Giving every Macedonian student a gateway to the world. In B. Bracey \& T. Culver (Eds.), Harnessing the potential of IT for education: A multistakeholder approach (pp. 113-119). New York, NY: United Nations IT Task Force.

State Statistical Office. (2003). Census of population, households, and dwellings in the Republic of Macedonia, 2002: Final data. Skopje, Macedonia. Retrieved from www.stat.gov.mk/pdf/10-2003/2.1.3.30.pdf

Strachan, G. (2007, 2008). Project Director, Macedonia Connects. Interviews with the author, October 1 and 23, 2007, June 17, 2008.

Stewart, A., \& Gray, T. (2006). The authenticity of "Type Two" multistakeholder partnerships for water and sanitation in Africa: When is a stakeholder a partner? Environmental Politics, 15(3), 362-378.

Weigel, G., \& Waldburger, D. (Eds.). (2004). IT4D: Connecting people for a better world: Lessons, innovations and perspectives of information and communication technologies in development. Berne: Swiss Agency for Development and Cooperation (SDC) and Global Knowledge Partnership (GKP).

World Bank. (2008). World Development Indicators. Data available from http://web.worldbank.org/ 